\title{
Clinical, histopathological and immunohistochemical features of brain metastases originating in colorectal cancer: a series of 27 consecutive cases
}

\author{
Viorel SCRIPCARIU ${ }^{1,2)}$, Delia Gabriela Ciobanu APOStol ${ }^{3,4)}$, Gabriela Florenta DUMitresCu ${ }^{5)}$, \\ MiHAELA DANA TURLIUC ${ }^{6,7)}$, ANCA SAVA ${ }^{3,5)}$
}

\author{
1) Department of General Surgery, Grigore T. Popa University of Medicine and Pharmacy, Iaşi, Romania \\ 2) $1^{\text {st }}$ Surgical Oncology Unit, Regional Institute of Oncology, Iaşi, Romania \\ ${ }^{3)}$ Department of Morpho-Functional Sciences I, Grigore T. Popa University of Medicine and Pharmacy, \\ Iaşi, Romania \\ 4) Department of Pathology, St. Spiridon Emergency County Hospital, Iaşi, Romania \\ 5) Department of Pathology, Prof. Dr. Nicolae Oblu Emergency Clinical Hospital, Iaşi, Romania \\ 6) Department of Surgery II, Grigore T. Popa University of Medicine and Pharmacy, Iaşi, Romania \\ 7) $2^{\text {nd }}$ Neurosurgery Clinic, Prof. Dr. Nicolae Oblu Emergency Clinical Hospital, Iaşi, Romania
}

\begin{abstract}
Introduction: Brain metastases (BMs) originating in colorectal cancer (CRC) have a significant importance for patients' survival. Because in literature there are only isolated case reports and only few series published on this issue, we aimed to assess the incidence of BMs from $\mathrm{CRC}$, to identify patient's characteristics and BMs clinical, histopathological (HP) and immunohistochemical (IHC) features, and to compare the data we obtained with those from literature. Patients, Materials and Methods: We present a retrospective study of 27 histologically confirmed cases of BMs from CRC among all 1040 patients who received metastasectomy in the Department of Neurosurgery, Prof. Dr. Nicolae Oblu Emergency Clinical Hospital, laşi, Romania, in an eight-year period (January 2011 to December 2018). Patients' characteristics (gender, age), primary tumor location, time from primary tumor surgery to BMs surgery and BMs features (number, location and HP characteristics) were investigated. Histochemical [Alcian Blue (AB) and Periodic Acid-Schiff (PAS)] staining and IHC stainings for cytokeratin (CK) 7, CK20, caudal-type homeobox 2 (CDX2) and human epidermal growth factor receptor 2 (HER2)/neu were performed on all available BMs specimens. Results: There were 27 consecutive patients with BMs from CRC, corresponding to $2.59 \%$ of all patients with BMs during the eight-year period we have studied, most of them being diagnosed and treated in 2016. Male:female ratio was 1.45 . The mean age for all patients at diagnosis of the BMs was 62.25 years (range: $40-79$ years). The origin of the primary cancer was mainly the colon $(62.96 \%$ of all cases). Of all 27 patients, only two (7.4\%) presented neurological symptoms without a diagnosis of CRC. BMs were identified in a period ranging from six months to 70 months after the initial diagnosis. The average time between diagnosis of the primary tumor and of the BMs was 25.92 months. At the moment of the diagnosis of BMs, 17 (62.96\%) patients also had other systemic metastases. Most of the cases $(55.55 \%)$ were situated in the supratentorial compartment. IHC stainings were negative for CK7 and positive for CK20 and CDX2 in all BMs from colonic adenocarcinomas (ADCs), a profile consistent with a non-neuronal and gastric origin. $A B$ and PAS stainings revealed pools of extracellular mucin, especially in cases of mucinous ADC. Ki67 labeling index ranged between $90 \%$ and $100 \%$. IHC staining with anti-HER2/neu antibody showed in $25(96.15 \%)$ cases a strong and diffuse aberrant nuclear staining. Conclusions: BMs originating in CRC represent a rare pathology and have particular clinical and IHC features that could vary from one series to another series. In a few cases, BMs may be diagnosed in the absence of a known CRC diagnosis and in these situations, the correct diagnosis is of interest. However, a panel of antibodies can help in establishing a correct diagnosis. Our study was among the first to analyze the HER2/neu expression pattern in BMs from CRC and we found a strong aberrant nuclear expression of this molecular marker on IHC investigation. Related to the data published so far in the literature, it is possible that HER2/neu aberrant expression in the tumor nuclei of the BMs from our series may express the metastatic tumor cell phenotype that was previously subjected to cytostatics and radiation therapies. As such, we suggest that HER2/neu aberrant expression in BMs originating in CRC could represent a proof for the worst prognosis of these patients.
\end{abstract}

Keywords: brain metastases, colorectal cancer, histochemistry, CK20, CDX2, HER2/neu.

\section{a Introduction}

From a clinically point of view, brain metastases (BMs) are the most significant tumors because even the presence of one alone can cause serious disability. These are the most common adult intracranial tumors and account for more than $50 \%$ of all brain tumors [1]. Currently, the incidence of BMs is increasing due to the early detection of small metastases by magnetic resonance imaging (MRI), due to the prolongation of the life of these patients by improving the management of the primary tumor as new therapies were recently introduced into the oncological practice, but also through the improvement of the screening [2].

BM may be the first sign of a previously undiagnosed cancer or may occur years after the primary cancer was diagnosed. Barnholtz-Sloan et al. analyzed the incidence proportion of BM related to the primary tumor among all patients diagnosed with cancer in the Metropolitan Detroit Cancer Surveillance System during a period of

This is an open-access article distributed under the terms of a Creative Commons Attribution-NonCommercial-ShareAlike 4.0 International Public License, which permits unrestricted use, adaptation, distribution and reproduction in any medium, non-commercially, provided the new creations are licensed under identical terms as the original work and the original work is properly cited. 
31 years (1973 to 2001). They found that $9.6 \%$ of all patients develop BM along the evolution of their disease. On the first places were lung cancer $(19.9 \%)$, followed by melanoma $(6.9 \%)$, kidney cancer $(6.5 \%)$, breast cancer $(5.1 \%)$ and colorectal cancer (CRC) (1.8\%) [1]. Nine years ago, we published an article about the incidence of BMs that were surgically treated in our Institution in correlation with the primary tumor that was excised in another hospital. We have found that tumors originating in lung cancers represented almost half of all cases, those from breast cancers represented a fifth part, those from skin cancers (especially melanoma) and genitourinary cancer represent each less than $10 \%$, but gastrointestinal carcinoma was diagnosed only in $2.62 \%$ of all cases. However, in $16.31 \%$ of cases, the primary tumor remained unknown, despite extensive investigation [3]. On the other hand, CRC is the third cancer-related deaths cause in developed countries, among males and females [4] and the fourth cause of death worldwide [5].

However, distant metastases occur frequently during the natural evolution of CRC, but BMs of this type of cancer are a rare event compared to the numbers of liver metastases (20-30\%) and lung metastases (10-20\%) [6].

A group of researchers from the University of Medicine and Pharmacy of Craiova, Romania, analyzed the significance of inflammatory reaction that they identified in peritumoral tissue in a series of stage III colon adenocarcinoma (ADC). They were able to prove that tumor cells and inflammatory cells interact one another in order to realize a special microenvironment useful for tumor proliferation [7].

There are authors who have reported percentages of BMs ranging from $0.6-3.2 \%[3,5,8]$, while other authors claim that BMs from CRC could represent even $4 \%$ to $6 \%$ of all BMs cases [9] or even $9 \%$, either synchronically or heterochronically [10], depending on the type of the analysis of cases (with imaging, histopathological (HP) or autopsy confirmation or without the confirmation of one of these investigation). For most of the patients with BMs $(80 \%)$, metastasis can develop after a variable period of time from the diagnosis of the primary CRC (metachronous presentation), but in some cases, BM can be diagnosed before (early presentation) or at the same time (synchronous presentation) with the primary cancer.

$\mathrm{BM}$ as the initial sign of primary CRC development, and in the absence of any liver and lung metastases, is a rare event and only a few cases have been published so far in the English literature [6].

In the case of CRC, BMs are late manifestations of the disease, being usually diagnosed in advanced stages of cancer. BMs are observed concomitantly or subsequently with liver ( $50 \%$ of cases) or pulmonary ( $80 \%$ of all cases) metastases [8]. BMs from CRC, like all other metastases that have as a starting point any other type of carcinoma, are associated with morbidity (considerable loss of autonomy due to neurocognitive and functional deficits) and a short survival for the patient (about 4-6 weeks in the absence of treatment and one year, maximum two years, under surgical treatment followed by chemotherapy and whole brain radiotherapy) [11-13]. However, patient's survival is visibly influenced by treatment, but the influence of the pathological factors is certainly not known. There are few reported data on the patients and tumor characteristics of BMs from CRC.

\section{Aim}

Our study was conducted to clarify the clinical and pathological characteristics of the BMs originating in $\mathrm{CRC}$ in order to be useful for an optimal management of these brain lesions.

\section{a Patients, Materials and Methods}

Using the databases of the Department of Pathology, Prof. Dr. Nicolae Oblu Emergency Clinical Hospital, Iaşi, Romania, we reviewed all patients with BMs diagnosed and treated during an eight years period (January 2011 to December 2018) in the same institution and selected only those with BM from CRC. From all 1040 cases with $\mathrm{BM}$ from any cancer, we identified 27 patients with BM from CRC.

For all 27 included patients, we retrieved data pertaining to gender and age at diagnosis, location of the primary tumor, characteristics of the BMs (number, location, and their pathological features), other systemic metastases, time interval between CRC diagnosis and identification of BMs. In addition, we have cut new sections at $4 \mu \mathrm{m}$ from the old paraffin blocks and realized histochemical reaction [Alcian Blue $(\mathrm{AB})$ and Periodic Acid-Schiff (PAS)] in order to identify the mucinous secretion, and immunohistochemical (IHC) staining in order to establish the colonic origin of the BM [anti-cytokeratin (CK) AE1/AE3, anti-CK7, anti-CK20, and anti-caudal-type homeobox 2 (CDX2) antibodies], the primary tumor as an ano-rectal melanoma [anti-S100, anti-human melanoma black 45 (HMB45), and anti-melan A antibodies], the tumor proliferative activity (anti-Ki67 antibody), but also to identify a possible correlation with treatment [antihuman epidermal growth factor receptor 2 (HER2)/neu antibody] (Table 1).

Table 1 - The antibodies used for immunohistochemical staining of the analyzed cerebral metastases

\begin{tabular}{|c|c|c|c|c|c|c|c|}
\hline Antibody & Manufacturer & Clone & $\begin{array}{l}\text { Antigen } \\
\text { retrieval }\end{array}$ & Class & Dilution & Labeling & $\begin{array}{c}\text { Cellular } \\
\text { localization }\end{array}$ \\
\hline Anti-CK AE1/AE3 & Dako & AE1/AE3 & $\begin{array}{l}\text { Citrate, } \\
\mathrm{pH} 6\end{array}$ & $\begin{array}{c}\text { Monoclonal mouse } \\
\text { anti-human CK AE1/AE3 }\end{array}$ & $1: 50$ & Epithelial cells & Cytoplasmic \\
\hline Anti-CK7 & Novocastra & RN7 & $\begin{array}{l}\text { Citrate, } \\
\mathrm{pH} 6\end{array}$ & $\begin{array}{c}\text { Monoclonal mouse } \\
\text { antibody }\end{array}$ & $1: 100$ & Epithelial cells & $\begin{array}{l}\text { Cytoplasmic and } \\
\text { membranous }\end{array}$ \\
\hline Anti-CK2O & Novocastra & KS208 & $\begin{array}{l}\text { Citrate, } \\
\mathrm{pH} 6\end{array}$ & $\begin{array}{l}\text { Monoclonal mouse } \\
\text { anti-human CK20 }\end{array}$ & $1: 100$ & Epithelial cells & Cytoplasmic \\
\hline Anti-CDX2 & Cell Marque & EPR2764Y & $\begin{array}{l}\text { Citrate, } \\
\mathrm{pH} 6\end{array}$ & $\begin{array}{l}\text { Monoclonal rabbit } \\
\text { antibody }\end{array}$ & $1: 500$ & $\begin{array}{l}\text { Intestinal } \\
\text { epithelium }\end{array}$ & Nuclear \\
\hline
\end{tabular}




\begin{tabular}{|c|c|c|c|c|c|c|c|}
\hline Antibody & Manufacturer & Clone & $\begin{array}{l}\text { Antigen } \\
\text { retrieval }\end{array}$ & Class & Dilution & Labeling & $\begin{array}{c}\text { Cellular } \\
\text { localization } \\
\end{array}$ \\
\hline Anti-HER2/neu & $\begin{array}{c}\text { Thermo Fisher } \\
\text { Scientific }\end{array}$ & SP3 & $\begin{array}{c}\text { Citrate, } \\
\mathrm{pH} 6\end{array}$ & $\begin{array}{c}\text { Monoclonal rabbit } \\
\text { antibody }\end{array}$ & $1: 700$ & Epithelial cells & Cell membrane \\
\hline Anti-S100 & Novocastra & - & - & $\begin{array}{l}\text { Polyclonal rabbit antibody } \\
\text { S100 protein }\end{array}$ & $1: 200$ & $\begin{array}{l}\text { Neural crest } \\
\text { cells }\end{array}$ & $\begin{array}{l}\text { Nuclear and } \\
\text { cytoplasmic }\end{array}$ \\
\hline Anti-HMB45 & Genemed & HMB45 & - & Mouse anti-melanosome & $1: 50$ & Melanic cells & Cytoplasmic \\
\hline Anti-melan A & Dako & A103 & $\mathrm{pH} 9$ & $\begin{array}{l}\text { Mouse monoclonal } \\
\text { anti-human melan A }\end{array}$ & $1: 50$ & Melanic cells & Cytoplasmic \\
\hline Anti-Ki67 & $\begin{array}{c}\text { Thermo Fisher } \\
\text { Scientific }\end{array}$ & SP6 & $\begin{array}{l}\text { Citrate, } \\
\mathrm{pH} 6\end{array}$ & $\begin{array}{c}\text { Monoclonal rabbit } \\
\text { antibody Ki67 }\end{array}$ & $1: 250$ & $\begin{array}{l}\text { Proliferating } \\
\text { cells }\end{array}$ & Nuclear \\
\hline
\end{tabular}

CK: Cytokeratin; CDX2: Caudal-type homeobox 2; HER2: Human epidermal growth factor receptor 2; HMB45: Human melanoma black 45.

\section{口 Results}

We identified 27 patients, who were surgically treated during the time period of the study for BMs of colorectal origin, representing only $2.59 \%$ from all patients with BM diagnosed and treated in our Institution (Figure 1). Of these, 16 were males, and 11 were females (male: female ratio 1.45 ).

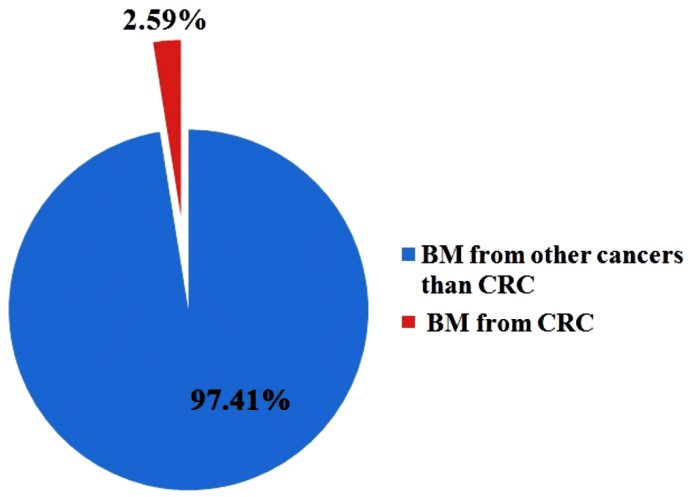

Figure 1 - Number of cases with BMs diagnosed and surgically treated between January 2011 and December 2018 in Prof. Dr. Nicolae Oblu Emergency Clinical Hospital, Iaşi, Romania. BMs: Brain metastases.

In our Institution, the number of BMs showed a progressive increase beginning with the year 2013, most cases being diagnosed in 2016 (Figure 2).

The mean age for all patients at diagnosis of the BMs was 62.25 years (range: $40-79$ years). Males patients were diagnosed with at least one intracranial metastasis at an average age of 59.625 years, but female patients were diagnosed at an older age, i.e., 66.09 years (range: 47-
79 years). The origin of the primary cancer was the colon (17 patients, 62.96\%), rectosigmoid (two patients, 7.4\%) and rectum (eight patients, 29.62\%) (Figures 3 and 4).

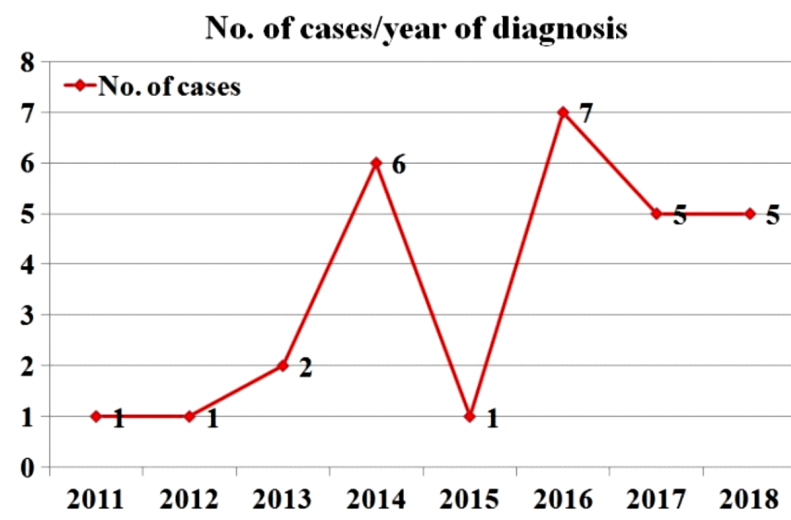

Figure 2 - Number of cases diagnosed in Prof. Dr. Nicolae Oblu Emergency Clinical Hospital, Iaşi, Romania, in a period of eight years (2011-2018). The red line represents the number of patients with BMs originating in CRC. BMs: Brain metastases; CRC: Colorectal cancer.

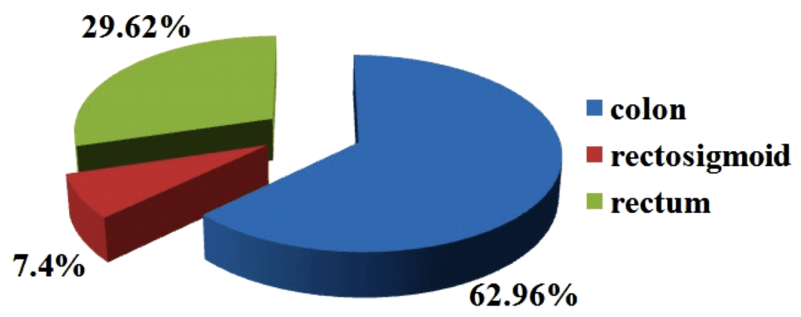

Figure 3 - BMs from CRC: distribution of primary tumor by anatomical site. BMs: Brain metastases; CRC: Colorectal cancer.
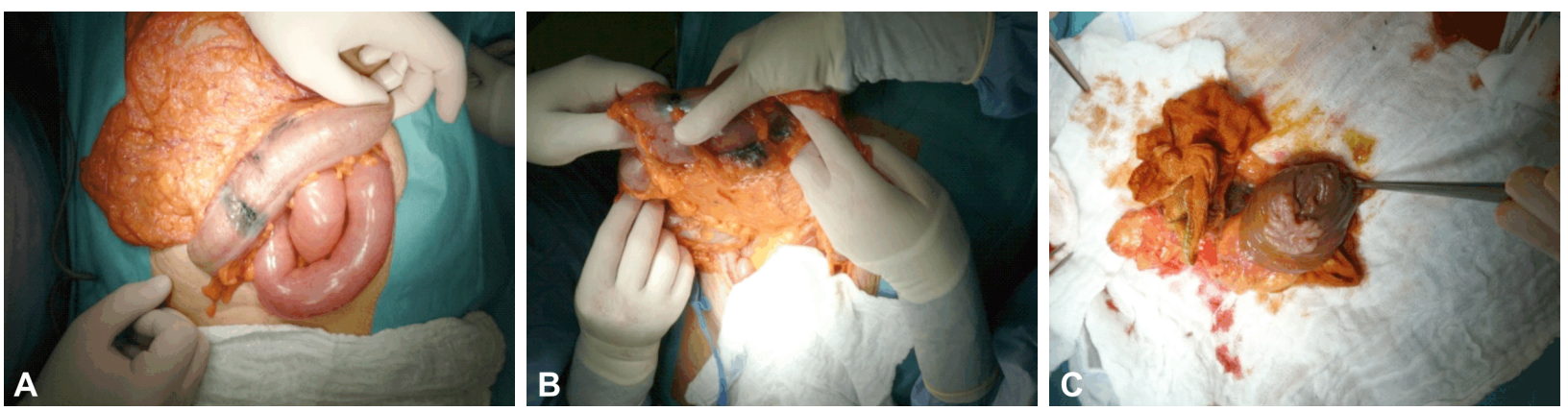

Figure 4 - Gross pathology of CRC specimens: $(A-C)$ Intraoperative images of a transverse colon carcinoma showed a clearly tumor infiltration of the bowel wall by an exophytic mass situated in the transverse colon and appearing as a bulky polypoid mass with rolled edges that was well-demarcated from the adjacent normal mucosa. The bowel lumen was narrowed and constricted due to an infiltrative exophytic tumor mass. CRC: Colorectal cancer. 


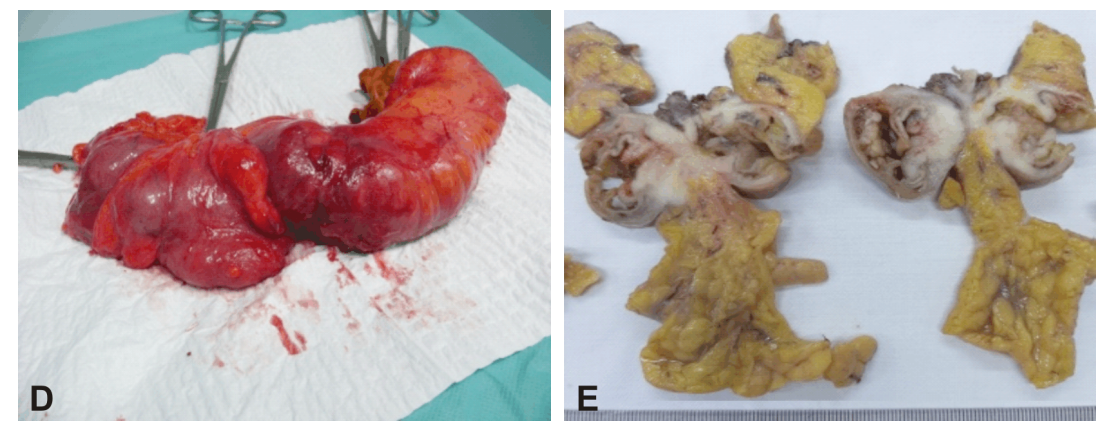

Figure 4 (continued) - Gross pathology of CRC specimens: (D) On the external side, excised segment of the ascending colon revealed an increase in volume and color change; (E) Gross morphology of an opened resection specimen representing a cecum cancer after fixation in 10\% neutral buffered formalin. The bowel lumen was narrowed and constricted due to an infiltrative exophytic tumor mass. CRC: Colorectal cancer.

Of all 27 patients, only two (7.4\%) presented neurological symptoms without a diagnosis of $\mathrm{CRC}$, and the subsequent surgical excision of the brain tumor and its pathological report led to the BM from CRC diagnosis. The remaining $25(92.59 \%)$ patients were known to have CRC when the BMs were diagnosed.

BMs were identified in a period ranging from six months to 70 months after the initial diagnosis. The average time between diagnosis of the primary tumor and of the BMs was 25.92 months. Twenty-three (85.18\%) patients with CRC developed BMs within five years after primary tumor diagnosis, $14(51.85 \%)$ of them being identified within the first year. Two patients $(7.4 \%)$ were diagnosed with BMs after five years from the primary tumor diagnosis and treatment (Figure 5). However, two $(7.4 \%)$ cases of BMs were diagnosed before the identification of the CRC.

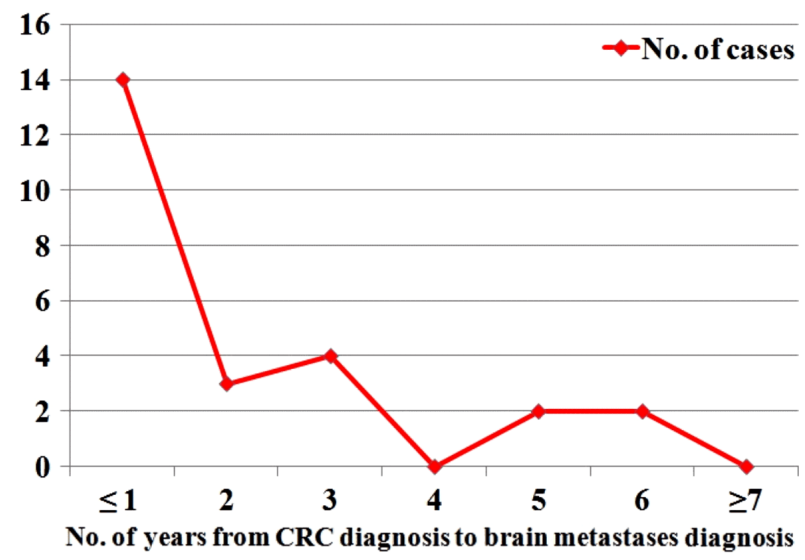

Figure 5 - The period of time between CRC diagnosis and BMs diagnosis. CRC: Colorectal cancer; BMs: Brain metastases.

At the moment of the diagnosis of BMs, 17 (62.96\%) patients also had other systemic metastases, mainly to lung - seven $(25.92 \%)$ patients and liver - three $(11.11 \%)$ patients, but also in other sites in seven $(25.92 \%)$ cases: bone - one case, abdominal-pelvic lymph nodes - one case, or an association of more than two anatomical sites - five cases. Brain was the unique site of metastasis in five $(18.51 \%)$ patients. Fifteen $(55.55 \%)$ patients were diagnosed with a single BM from CRC, and 12 (44.45\%) patients presented two or more lesions.

The supratentorial compartment was involved in 15 $(55.55 \%)$ patients; the infratentorial compartment was involved in eight $(29.62 \%)$ cases; and in four (14.81\%) cases, the lesions involved both compartments (Figure 6).

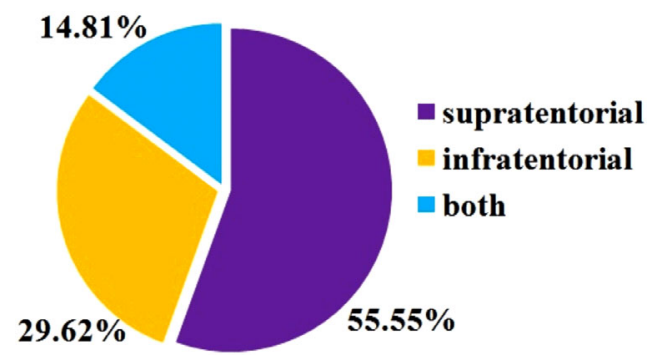

Figure 6 - Distribution of patients according to location of BMs (supratentorial vs. infratentorial). BMs: Brain metastases.

The tumor mass/masses was/were resected with a favorable post-operative course and resolution of neurological symptoms. Pathology revealed metastatic colorectal ADCs in $26(96.29 \%)$ patients and a metastatic ano-rectal melanoma in one case $(3.7 \%)$ (Figures 7-12). IHC stainings were negative for CK7 and positive for CK20 and CDX2 in all BMs from colonic ADCs, a profile consistent with a non-neuronal, and gastric origin. $\mathrm{AB}$ and PAS staining revealed pools of extracellular mucin, especially in cases of mucinous ADC, but also in some areas of conventional ADC. Ki67 labeling index (LI) ranged between $90 \%$ and $100 \%$. IHC staining with antiHER2/neu antibody showed negativity in one case (3.84\%) of all 26 metastatic colonic ADC, but all other 25 (96.15\%) cases of metastatic ADC expressed positivity in an aberrant manner, i.e., strong and diffuse nuclear staining (Table 2).

The final pathological diagnosis corresponded to BMs from colorectal ADC in $26(96.29 \%)$ patients, and from a recto-anal epithelioid melanoma in one patient (3.7\%). From all $26 \mathrm{ADCs}$, the conventional type was diagnosed in $17(65.38 \%)$ patients, serrated subtype in five $(19.23 \%)$ patients, mucinous type in three $(11.53 \%)$ patients, cribriform comedo-type in one patient $(3.84 \%)$ (Figure 13). 

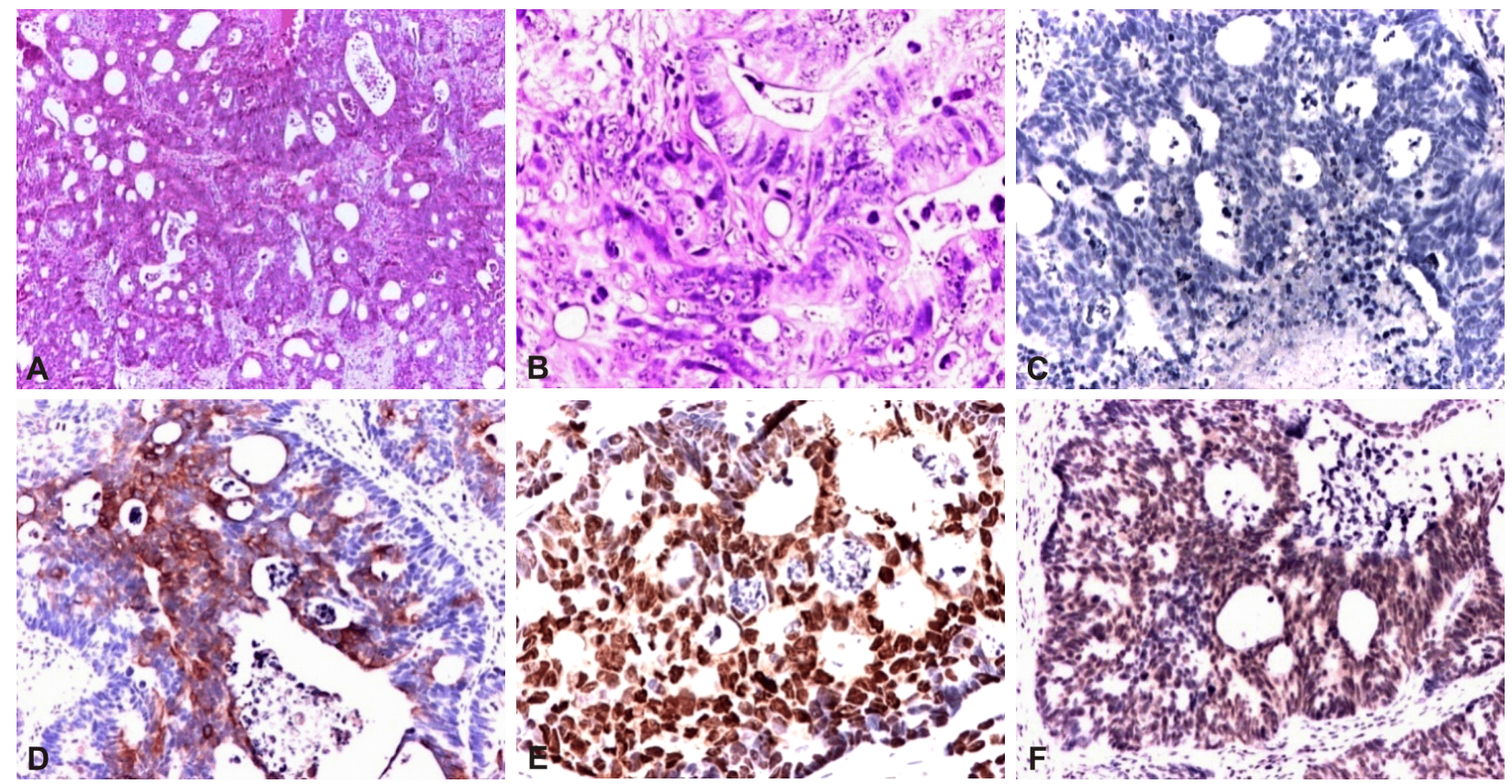

Figure $7-F$, 73-year-old. Left frontal metastasis from a rectal ADC operated and treated with chemo-radiotherapy two years ago: (A) Moderately differentiated colorectal ADC showing glands or tubules, simple, complex or slightly irregular, filled with necrotic debris ("dirty necrosis") (HE staining, $\times 40)$; (B) Irregular glands or tubules with nuclear polarity lost and many atypical mitoses (HE staining, $\times 200)$; (C) Anti-CK7 antibody negative immunostaining of the tumor cells $(\times 100)$; (D) AntiCK20 antibody intense cytoplasmic immunostaining with brown particles in the tumor cells; (E) CDX2 high expression in the nuclei of the tumor cells $(\times 200)$; (F) Anti-HER2/neu antibody negative immunostaining ( $\times 100)$; (G) Ki67 high expression (90\%) in the nuclei of tumor cells $(\times 100)$. F: Female; ADC: Adenocarcinoma; HE: Hematoxylin-Eosin; CK: Cytokeratin; CDX2: Caudal-type homeobox 2; HER2: Human epidermal growth factor receptor 2.
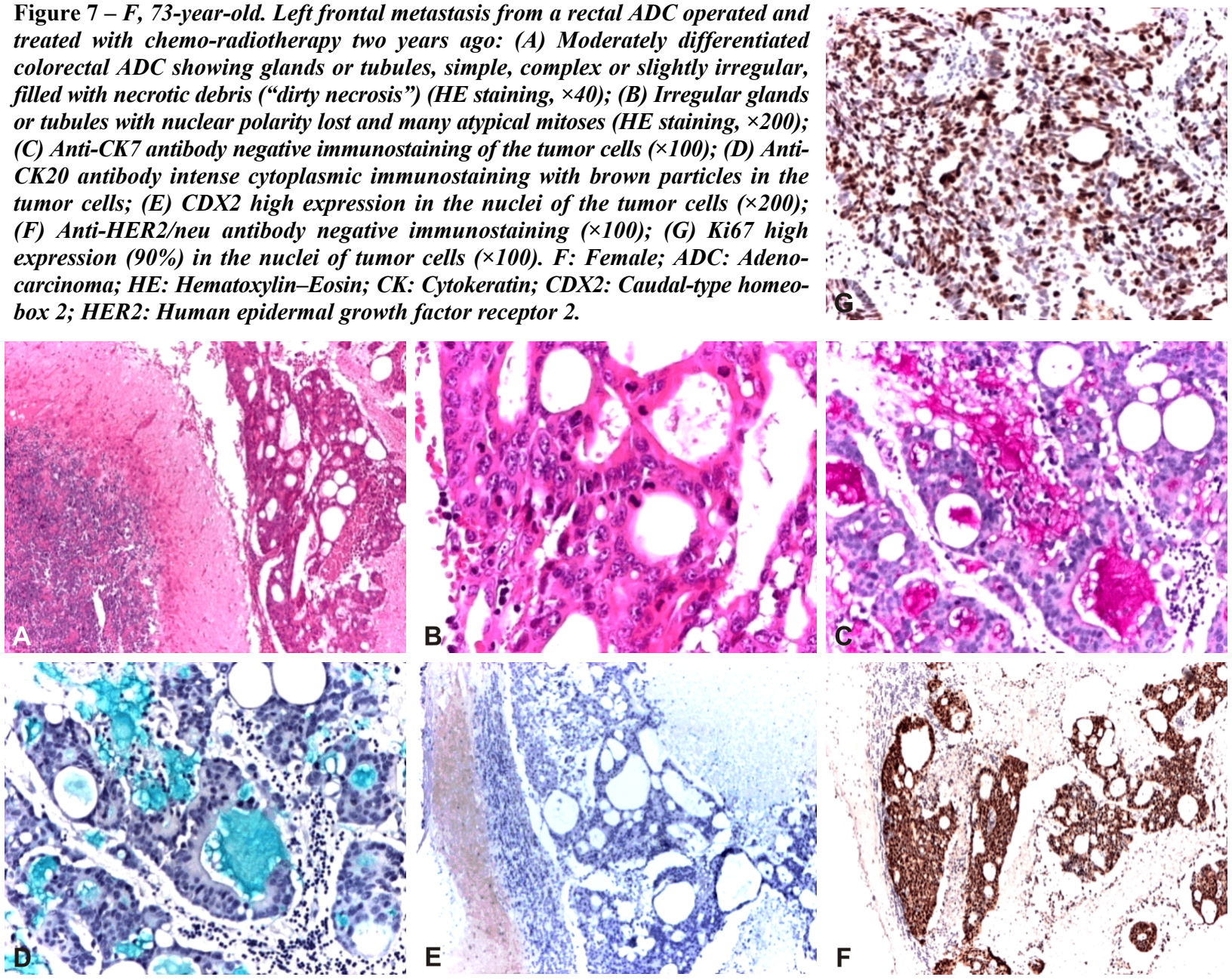

Figure 8 - F, 79-year-old. Left cerebellar metastasis from a rectal ADC operated and treated with chemo-radiotherapy three years ago before: (A) Conventional moderately differentiated colorectal ADC that was well delimitated from the adjacent cerebellar tissue (HE staining, $\times 40)$; (B) Irregular glands or tubules showing tumor epithelial cells with nuclear polarity lost and many atypical mitoses (HE staining, $\times 200)$; (C) Histochemical staining identified intratumoral, but extracellular neutral mucins (PAS staining, ×100); (D) Histochemical staining identified acid mucins, especially into the lumen of the tumor tubular structures (Alcian Blue staining, $\times 100$ ); (E) Tumor cells were negative for CK7, but the adjacent cerebellar tissue expressed moderate staining ( $\times 400)$; $(F)$ High expression for CDX2 in tumor glandular epithelial cells (×40). F: Female; ADC: Adenocarcinoma; HE: Hematoxylin-Eosin; PAS: Periodic Acid-Schiff; CK7: Cytokeratin 7; CDX2: Caudal-type homeobox 2. 


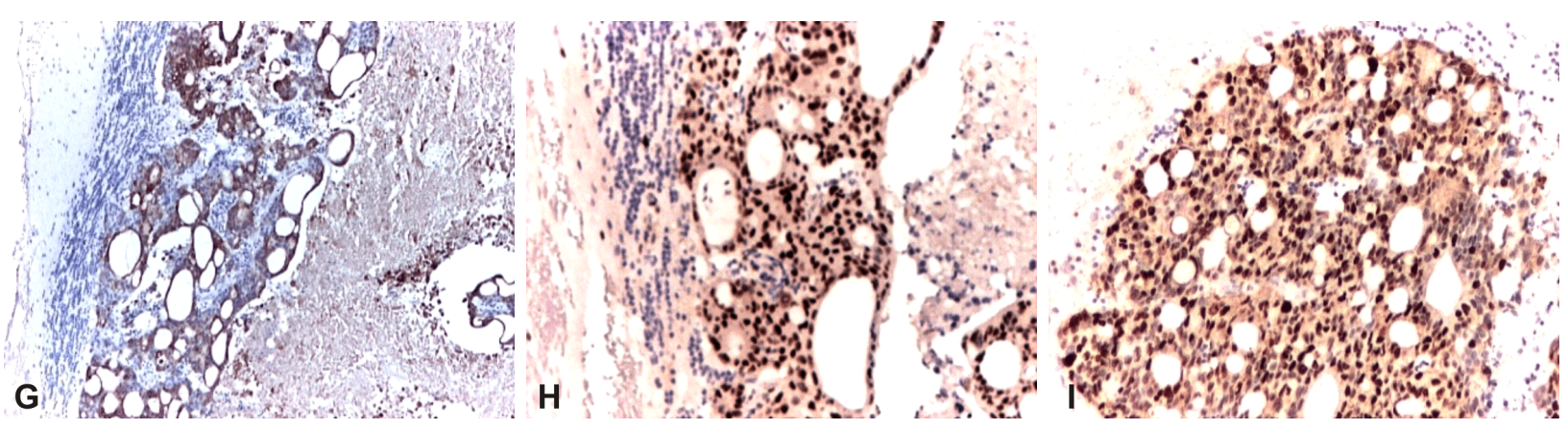

Figure 8 (continued) - F, 79-year-old. Left cerebellar metastasis from a rectal ADC operated and treated with chemoradiotherapy three years ago before: $(G)$ CK20 positivity in the cytoplasm of the tumor cells $(\times 40)$; (H) Aberrant nuclear immunomarking of the tumor cells with anti-HER2/neu antibody ( $\times 100)$; (I) Ki67 high expression (95\%) in the nuclei of tumor cells ( $\times 100)$. F: Female; ADC: Adenocarcinoma; CK20: Cytokeratin 20; HER2: Human epidermal growth factor receptor 2.
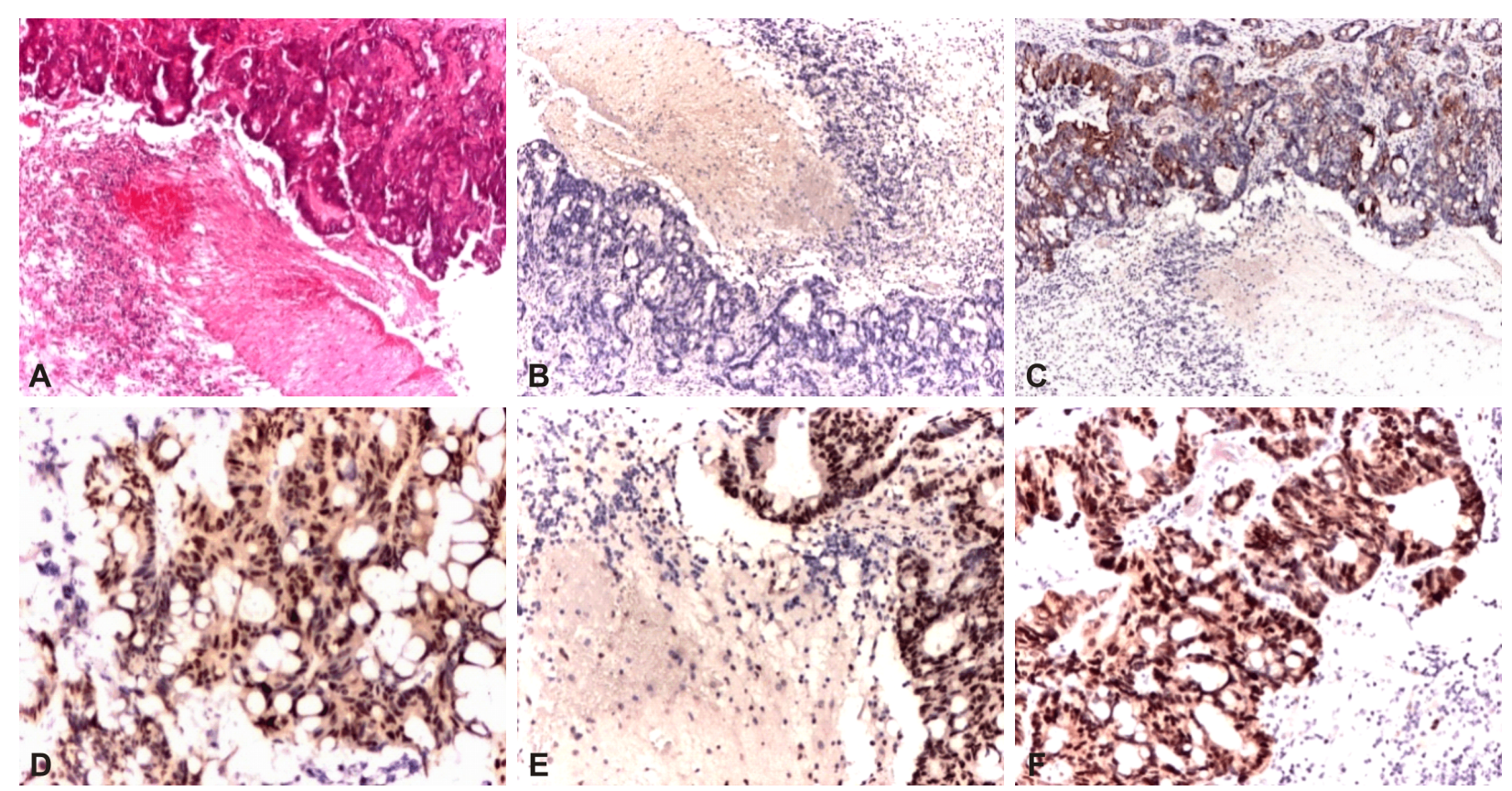

Figure 9-M, 56-year-old. Right cerebellar metastasis from an ascending colon ADC operated and treated with chemoradiotherapy one year ago: (A) Moderately differentiated colorectal ADC (HE staining, $\times 40)$; (B) Tumor cells ADC did not displayed cytoplasmic immunoreactivity for CK7 ( $\times 40)$; (C) Diffuse and strong CK20 immunoreactivity in the cytoplasm of tumor cells (×40); (D) Diffuse and strong nuclear expression of CDX2 in the nuclei of tumor cells $(\times 100)$; (E) Aberrant nuclear immunomarking of the tumor cells with anti-HER2/neu antibody ( $\times 100)$; (F) Ki67 high expression (100\%) in the nuclei of tumor cells (×100). M: Male; ADC: Adenocarcinoma; HE: Hematoxylin-Eosin; CK: Cytokeratin; CDX2: Caudal-type homeobox 2; HER2: Human epidermal growth factor receptor 2.
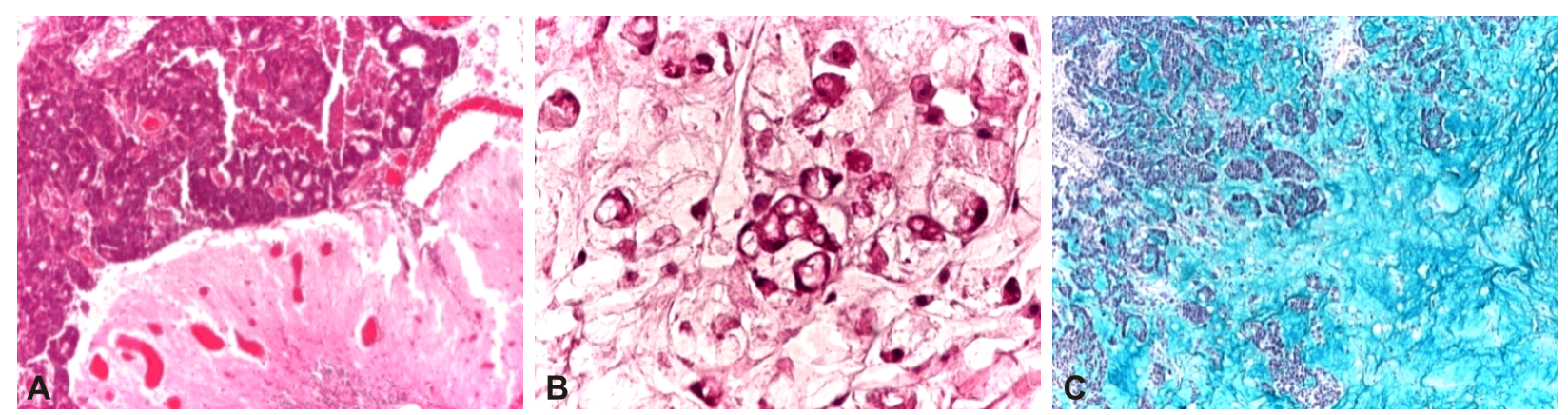

Figure 10 - M, 47-year-old. Right cerebellar metastasis from a transverse colon ADC operated and treated with chemoradiotherapy three years ago: (A) Area of conventional moderately differentiated colorectal ADC was well delimited from the adjacent cerebellar tissue (HE staining, $\times 40$ ); (B) Large areas of mucinous (colloid) carcinoma giving prominence to signet ring cells (cells with prominent intracytoplasmic mucin and displacement of the nucleus) floating in large pools of mucin (HE staining, $\times 200)$; (C) Abundant extracellular acid mucin associated with ribbons or tubular structures of neoplastic epithelium (Alcian Blue staining, ×40). M: Male; ADC: Adenocarcinoma; HE: Hematoxylin-Eosin. 

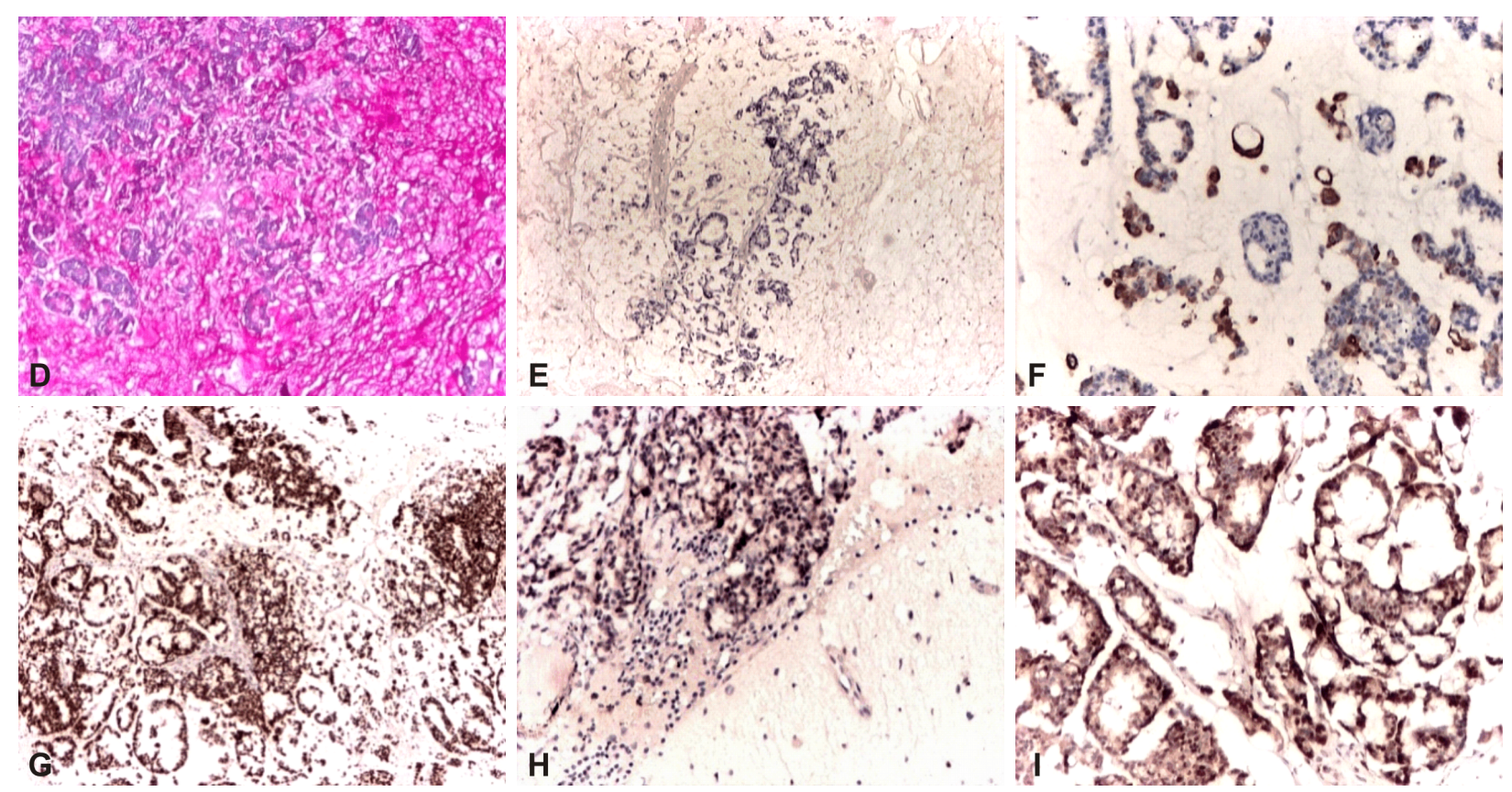

Figure 10 (continued) - M, 47-year-old. Right cerebellar metastasis from a transverse colon ADC operated and treated with chemo-radiotherapy three years ago: (D) Abundant extracellular neutral mucin (PAS staining, $\times 40)$; (E) Tumor cells did not display cytoplasmic immunoreactivity for CK7 ( $\times 40)$; (F) Focal strong CK20 immunoreactivity in the cytoplasm of cancer cells ( $\times 40)$; (G) Diffuse and strong nuclear expression of CDX2 in the nuclei of cancer cells ( $\times 100)$; (H) Aberrant nuclear immunomarking of the tumor cells with anti-HER2/neu antibody $(\times 100)$; (I) Ki67 high expression (90\%) in the nuclei of tumor cells (×100). M: Male; ADC: Adenocarcinoma; PAS: Periodic Acid-Schiff; CK: Cytokeratin; CDX2: Caudal-type homeobox 2; HER2: Human epidermal growth factor receptor 2.
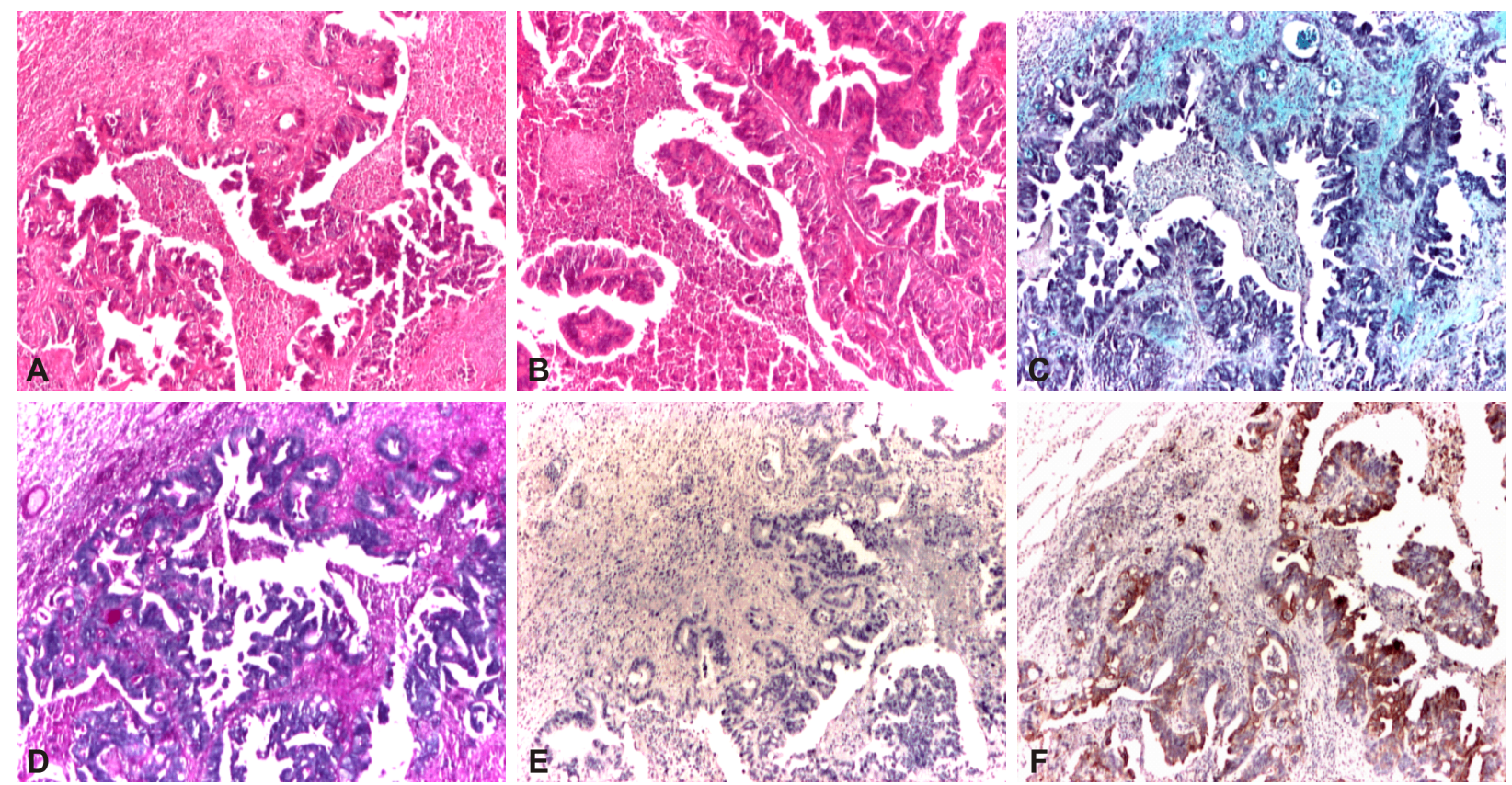

Figure 11 - M, 69-year-old. Cerebral intraventricular metastasis from an ascending colon ADC operated and treated with chemo-radiotherapy 17 months ago: (A) Serrated-type colorectal ADC showing epithelial serrations (HE staining, $\times 40$ ); (B) Same tumor displaying villous structures (HE staining, $\times 40)$; (C) Histochemical staining identified areas of intratumor extracellular acid mucins (Alcian Blue staining, $\times 40)$; (D) Histochemical staining identified areas of intratumor extracellular neutral mucins (PAS staining, $\times 40)$; (E) Tumor cells did not display cytoplasmic immunoreactivity for CK7 (×40); (F) Focal strong CK20 immunoreactivity in the cytoplasm of tumor cells (×40). M: Male; ADC: Adenocarcinoma; HE: Hematoxylin-Eosin; PAS: Periodic Acid-Schiff; CK: Cytokeratin. 


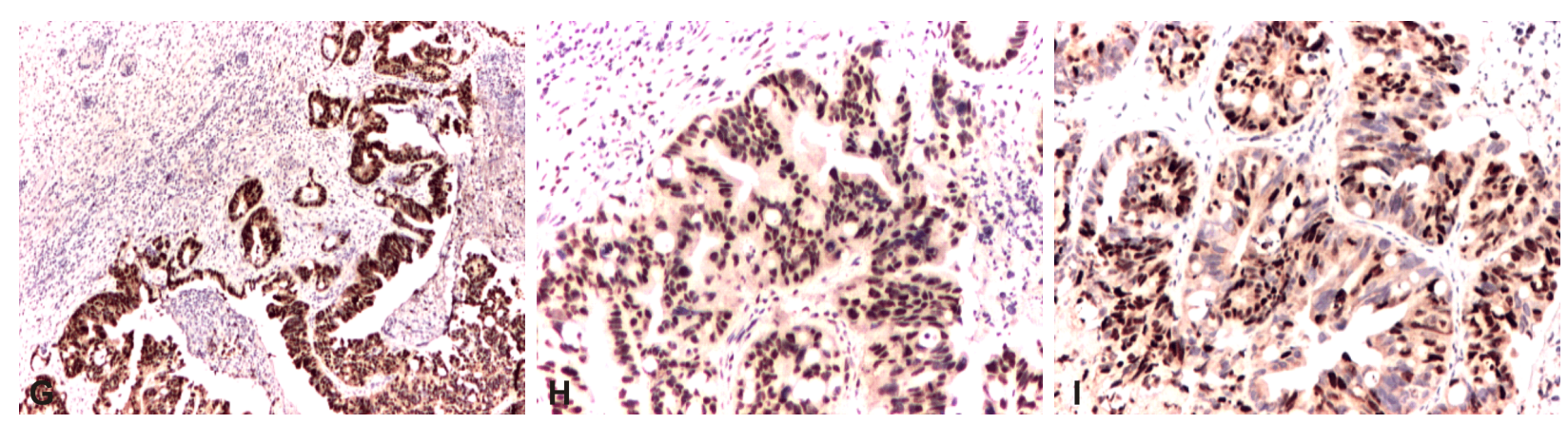

Figure 11 (continued) - M, 69-year-old. Cerebral intraventricular metastasis from an ascending colon ADC operated and treated with chemo-radiotherapy 17 months ago: (G) Diffuse and strong nuclear expression of CDX2 in the nuclei of tumor cells ( $\times 100)$; (H) Aberrant nuclear immunomarking of the tumor cells with anti-HER2/neu antibody $(\times 100)$; (I) Ki67 high expression (95\%) in the nuclei of tumor cells ( $\times 100)$. M: Male; ADC: Adenocarcinoma; CDX2: Caudaltype homeobox 2; HER2: Human epidermal growth factor receptor 2.
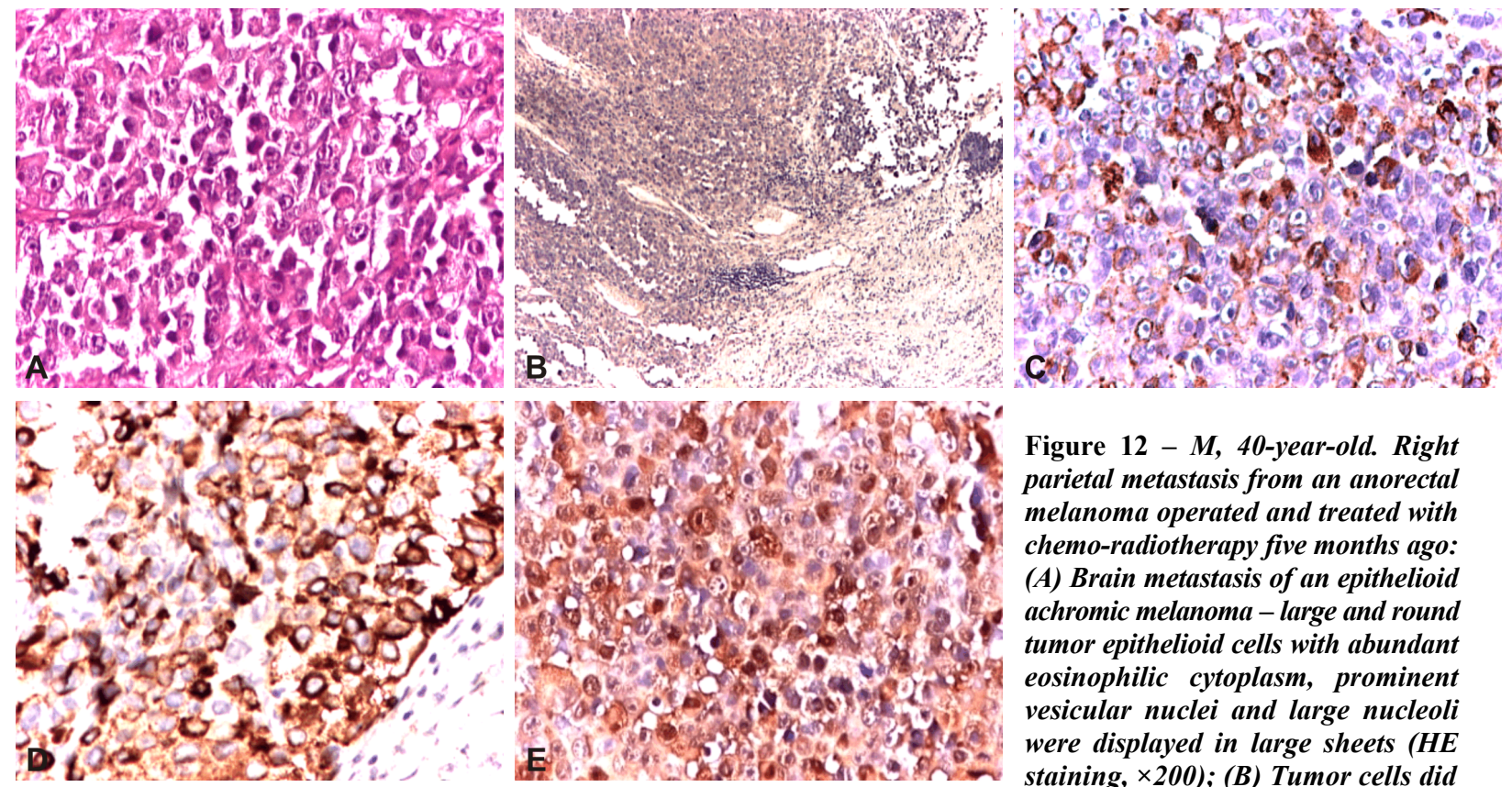

Figure 12 - M, 40-year-old. Right parietal metastasis from an anorectal melanoma operated and treated with chemo-radiotherapy five months ago: (A) Brain metastasis of an epithelioid achromic melanoma - large and round tumor epithelioid cells with abundant eosinophilic cytoplasm, prominent vesicular nuclei and large nucleoli were displayed in large sheets $(\mathrm{HE}$ staining, ×200); (B) Tumor cells did not display cytoplasmic immunoreactivity for CK AE1/AE3 ( $\times 40)$; (C) Tumor cells displayed strong and diffuse cytoplasmic immunoreactivity for HMB45 (×200); (D) Tumor cells displayed diffuse cytoplasmic immunoreactivity for melan $A$ (×200); (E) Tumor cells displayed diffuse cytoplasmic immunoreactivity for S100 protein $(\times 200)$. M: Male; HE: Hematoxylin-Eosin; CK: Cytokeratin; HMB45: Human melanoma black 45.

Table 2 - Immunohistochemical profile of BMs from CRC

\begin{tabular}{|c|c|c|c|c|c|c|c|c|}
\hline $\begin{array}{l}\text { Histological type } \\
\text { of BM from CRC }\end{array}$ & CK7 & CK20 & CDX2 & $\begin{array}{c}\text { HER2/neu (aberrant } \\
\text { nuclear accumulation) }\end{array}$ & $\begin{array}{c}\text { Ki67 LI } \\
(\%)\end{array}$ & Melan A & HMB45 & $\begin{array}{l}\mathrm{S} 100 \\
\text { protein }\end{array}$ \\
\hline \multicolumn{9}{|l|}{$A D C$} \\
\hline $\begin{array}{l}\text { - Conventional } \\
\text { type, moderately } \\
\text { differentiated }\end{array}$ & - & +++ & +++ & $+++/++/-$ & $90-100 \%$ & - & - & - \\
\hline - Serrated & - & +++ & +++ & +++ & $95 \%$ & - & - & - \\
\hline - Mucinous & - & +++ & +++ & +++ & $90 \%$ & - & - & - \\
\hline $\begin{array}{l}\text { - Cribriform } \\
\text { comedo-type }\end{array}$ & - & +++ & +++ & +++ & $95 \%$ & - & - & - \\
\hline Melanoma & - & - & - & - & It was not done & +++ & +++ & +++ \\
\hline
\end{tabular}

BM: Brain metastasis; CRC: Colorectal cancer; CK: Cytokeratin; CDX2: Caudal-type homeobox 2; HER2: Human epidermal growth factor receptor 2; LI: Labeling index; HMB45: Human melanoma black 45; ADC: Adenocarcinoma. 


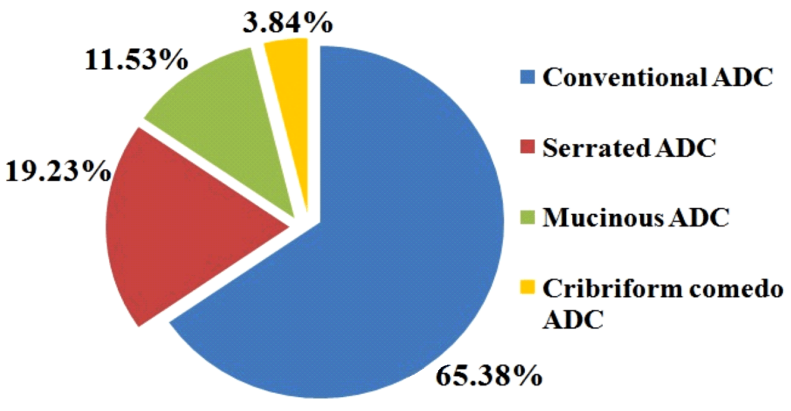

Figure 13 - Distribution of BM cases according to their histopathological diagnosis. BM: Brain metastasis; ADC: Adenocarcinoma.

\section{a Discussions}

Some authors consider that CRC, like other types of cancer, could be a growing pathology mainly due to soil pollution, which plays a vital role in ensuring the food [14]. A Spanish group of researchers from Cancer and Environmental Epidemiology Unit, National Centre for Epidemiology, from Madrid, realized an ecological study in order to examine CRC mortality at a municipal level (8098 Spanish towns), over the period 1997-2006, because they considered that pollution can be a factor that intervenes in the development of this type of cancer. The authors identified a statistically significant risk of CRC development for people who lived in the vicinity of several types of industries, such as mining, paper and wood mills, food and beverage plants, metal and ceramic production and processing facilities [15].

BMs are a common manifestation of systemic cancers and represent a significant percentage among all malignancies affecting the nervous system. BMs originate in lung and breast cancers, but those originating in CRC are rare, as the published values range between $0.1-4 \%$ $[1,16,17]$.

Mongan et al. analyzed a series of 39 histologically confirmed cases of BM from CRC diagnosed over a 23year period at a neurosurgical center in Rochester, NY, USA. The incidence of BM from CRC was $2.3 \%$, which is almost the same value obtained by us $(2.59 \%)$ [8].

BMs from CRC are rare as a tumor entity $[18,19]$. Probably a small percentage of CRC present BMs in their evolution due to the fact that the tumor cells must first pass through the circulation of the pulmonary capillaries to reach the brain and that is why the lung is the most frequent site of metastasis. However, the second pathway of hematogenous metastasis may also be the penetration of tumor cells into the systemic circulation directly through the drainage veins. Thus, they reach the cerebral circulation without the interposition of other small vessels.

The largest series from BM from $\mathrm{CRC}$ is that of Wroński \& Arbit, which consists of 73 patients with histologically confirmed CRC and BMs, which were surgically resected in a single institution. In their series there was a slightly higher predominance of female patients (female:male ratio 1.43), with a median age of 61.5 years unlike many other studies, including the present study, which reported a male predominance [20].
Like other studies that have stated that BM from CRC were diagnosed on average 27.6 months to 28.3 months after the primary tumor $[20,21]$, we also found an average of 25.92 months, but most of them developed within the first five years after primary tumor diagnosis.

Damiens et al. analyzed 48 patients who developed BMs from CRC. In their series, the gender (male:female ratio 25:23) was almost equal, which is also a particularity. The patients' median age at diagnosis of their BMs was 63 years, which is very close of that identified in our study (62.5 years old). Their youngest patient was 37 years old and the oldest was 84 [11]. Comparative, in our study the youngest patient was 40 and the older was 79 . However, we found out that male patients had an average age of 59.625 years old, but female patients were diagnosed at an older age (66.09 years old). Damiens et al. also reported that the median interval between diagnosis of the primary tumor and identification of the BMs was 24 months, which is very comparable with that obtained by us (25.92 months). Regarding the location of the primary tumor, these authors found out that the primary tumor originated in almost half of the cases in the rectum. This data is different from some other data-reporting colon on the first place. At diagnosis of BMs, almost all of their patients $(90 \%)$ also had other systemic metastases, mainly to lung (64\%) and liver (50\%) [11]. In our series, only two-thirds of patients presented systemic metastases, but lung and liver were the most interested sites.

Some authors reported that cerebellum was most the frequently involved site [8, 22], but Damiens et al. reported that the supratentorial compartment was two times more often affected by metastases from CRC than infratentorial compartment [11] and this distribution was the same in our series.

Most patients in the Mongan et al.'s series had pulmonary metastases at the time of the diagnosis of BMs [8], but in our series only two-thirds presented extracranial metastases and only a quarter of all patients had lung metastases.

Aprile et al. (2009) analyzed a series of 30 patients who underwent neurosurgical resection followed by wholebrain radiotherapy during a 9-year period in the Hospital of Udine, Italy. Median age at the time of surgery was 66 years, most patients (87\%) having concomitant lung and/or liver metastases. Neurosurgical resection and wholebrain radiotherapy resulted in a survival of almost two years [12].

An extensive research on BMs from CRC was conducted by a group of Chinese researchers. They studied a series of 45 patients who developed BMs and reported that most of their BMs originated in rectal cancer $(64.4 \%)$ and $80 \%$ of all 45 cases already had extracranial metastases at the time of BMs diagnosis. The most common extracranial metastatic sites were the lung $(57.8 \%)$, followed by the liver $(35.6 \%)$. All BMs from CRC with hepatic metastases were located in the supratentorial compartment, while $44.8 \%$ of all patients without hepatic metastases had infratentorial BMs.

The interval time from the diagnosis of $\mathrm{CRC}$ to the development of BMs varied depending on the Duke's stage of the CRC and the presence or absence of extracranial metastases. Patients' survival varied with Duke's stage 
of the primary $\mathrm{CRC}$, with presence or absence of the extracranial metastases (in liver or lung), with the number of BMs and type of received therapy, because the median survival time of the chemo-radiotherapy group was longer than that of monotherapy [23].

Christensen et al. (2016) conducted a systematic review on BMs. The authors concluded that BMs represent a late event in the development of a CRC, but there are several risk factors for the development of BMs, namely: young age, primary rectal localization and presence of pulmonary metastases. In addition, there are also some molecular factors of BMs development, i.e., Kirsten rat sarcoma viral oncogene homolog $(K R A S)$, B-raf protooncogene, serine/threonine kinase $(B R A F)$ and neuroblastoma V-Ras oncogene homolog (NRAS) mutations, but also an increase in carcinoembryonic antigen (CEA) and carbohydrate antigen 19-9 (CA 19.9) levels [5]. However, from their analysis it can be seen that the average age of patients with BMs ranged between 55.7 and 73 years, but the majority of their patients were in the seventh decade [5], more likely as in our study. Tevlin et al. published a series of 11 cases of BMs from CRC, which had radiological and pathological confirmation and demonstrated particular aspects [22]. Those cases represented only $0.3 \%$ of the total number of $\mathrm{BMs}$ diagnosed over a 24-year period (1988-2012) in a tertiary referral hospital from Dublin, Ireland. The mean age of patients at the time of primary tumor diagnosis was 70 years (range: $55-80$ years), but at the time of BMs diagnosis was 73 years (range 56-83 years). These authors found a predominance of male patients (male:female ratio was 2.66) [22]. In our institution, BMs represented a small percentage, most cases being diagnosed in recent years, probably due to the technical modernization of the Hospital, both in terms of equipping the operating rooms, as well as the radiology and pathology services, but also due to the highly specialized staff.

Although most authors have shown that at the time of the diagnosis of BMs, most patients already have had other systemic metastases (mainly in liver and lung) [11], Wroński \& Arbit reported that the presence of lung metastases had no impact on survival. In addition, these authors found out that only the presence of cerebellar BMs was associated with decreased survival [20].

Some authors reported that female gender appears to be slightly more frequently interested in BMs from CRC [23], but in most studies published so far male predominates [24], as in our series.

However, almost 10 years ago, we reported the epidemiological and pathological features of CRC detected on colonoscopy in asymptomatic patients, but with positive biopsies, which were residents in the same region, i.e., Moldavia, as the patients we actually investigate in the present study. Mean age of those patients were 64.125 years (range: 53-78 years) [25]. Because the patients included in the present study already have BMs and are younger than anterior group we can conclude that the younger the age at diagnosis of the $\mathrm{CRC}$, the greater the risk of progressing more rapidly and developing systemic metastases, especially in the brain. On HP examination, our previous article [25] revealed that $75 \%$ of all cases were found to be conventional ADCs, with well-differentiated tumors constituting the largest group $(50 \%)$. ADC with colloid features (mucinous type from today classification) represented $12.5 \%$ of all cases and it was especially detected in the proximal part of the colon. Also, 12.5\% of all cases were colloid carcinoma.

Another group of Romanian researchers from the University of Medicine and Pharmacy of Craiova, Romania, investigated $317 \mathrm{CRC}$ patients and found out that there was a slightly higher incidence in the number of women $(n=166,52.35 \%)$ than males $(n=151,47.65 \%)$. Most of these patients were in their $7^{\text {th }}$ decade of life. From a HP point of view, $311(98.11 \%)$ cases were ADCs, and only six $(1.89 \%)$ cases were carcinoid. From the total of 245 ADC, one third was represented by well-differentiated type, half of the cases were moderately differentiated type, and $12.65 \%$ of the cases were poorly differentiated type [26].

In general, the most common histological type of CRC that metastasizes is ADC. Mucinous ADC and serrated $\mathrm{ADC}$ are more rarely diagnosed in metastases originated in CRC and this fact determined Wang et al. (2020) to consider the seed and soil hypothesis, which suggests that the most important role belongs to the chemical composition of the microenvironment of the target organs in which those tumors will preferentially metastasize [27].

In the case of a BM, there is often the situation of a differential diagnosis regarding the origin of the primary cancer. The use of appropriate IHC antibodies panel can help identify the origin of most BMs. There are several markers of reported utility in the determination of the primary gastrointestinal source of a metastatic ADC to the brain. CK7-/CK20+/CDX2+ immunophenotype is considered as pattern of metastatic CRC [28] even when poorly differentiated. We also found a specific combination of CK7-/CK20+/CDX2+ immunostainings that clarified the gastrointestinal origin of the BMs.

CDX2 is an intestine-specific transcription factor that is expressed in tumors of the intestine, from the duodenum to the rectum [29]. It shows strong nuclear expression in up to $90 \%$ of colorectal and duodenal ADC [30]. CDX2 is known to exert a tumor-suppressor role in CRCs and as such, it is regarded as a specific marker for the identification of the colorectal origin of a metastatic ADC [31].

Shigematsu et al. (2018) investigated the prognostic role of CDX2 immunoexpression as a potential biomarker for high-risk recurrence in early stages of a CRC. These authors reported that the CDX2-low CRC has a higher metastatic potential, and as such the patient would have a poor prognosis [32]. However, our study has demonstrated a high expression of CDX2 in BM from CRC and this aspect could explain the poor prognosis of the patients who underwent curative brain metastasectomy.

HER2/neu is a proto-oncogene located on chromosome 17q21 that encodes ErbB-2, a 185-kDa transmembrane tyrosine kinase receptor. HER2 gene amplification and overexpression of HER2/neu has been associated with pathogenesis and progression of several human cancers [33].

Schuell et al. reported that HER2/neu staining (moderately and strongly positive) was detected only in primary tumors of patients with confirmed metastases [34]. In cases with HER2/neu overexpression, Sayadnejad et al. 
did not find any significant correlation between the stage of tumors and the expression of HER2/neu [35], but Shabbir et al. find such a correlation [33].

However, information on the HER2/neu expression in $\mathrm{BM}$ from CRC is currently lacking. Along the time, there were controversies about the levels of HER2/neu overexpression in patients with CRC. There are articles showing strong positivity (range: $30-83 \%$ ) in primary CRC, but also some others who found only $1.6 \%$ of their 1645 cases to be HER2/neu positive [33-36]. There are some studies reporting a worse prognosis for HER2/neu positive CRC patients [37, 38].

There are studies that have analyzed the significance of HER2/neu positivity for primary CRC as well as for liver metastases from a CRC. Aprile et al. from the University Hospital of Udine, Italy, found a significant correlation between CRC stage and HER2/neu positivity, HER2/neu being more common in advanced stage. Also, HER2/neu positivity was associated with the development of liver metastases. These authors also found out that the rate of HER2/neu positivity was $8.1 \%$ for the primary CRC tumors and $12 \%$ for their corresponding BMs and the survival of these patients correlated well with the degree of immunopositivity as median overall survival after neurosurgery was 6.5 months for HER2/neu score 0 vs. 4.6 months for HER $2 /$ neu score $1+/ 2+/ 3+$. These authors pointed out that HER2/neu expression in BMs originating in CRC could have a potential negative prognostic value [38]

Recently, it has been attempted to determine the genomic signature of BMs originating in CRC. A group of Chinese researchers analyzed comparatively wholeexome sequencing (WES) and whole-genome sequencing (WGS) data for primary CRC tumors, BMs related to these cancers, and adjacent normal tissue. They found elevated mutational signatures in BMs, but not in primary CRC [39]. Also, Battaglin et al. from the University of South Carolina, USA, highlighted the fact that genomic analyses revealed that BM can harbor potentially unique driver mutations, which are different from those of the primary CRC [40]. These authors found out that the most frequently mutated genes in $\mathrm{BM}$ from $\mathrm{CRC}$ were tumor protein p53 (TP53), adenomatous polyposis coli (APC), $K R A S$, AT-rich interaction domain 1A (ARIDIA), phosphatidylinositol-4,5-bisphosphate 3-kinase catalytic subunit alpha $(P I K 3 C A)$ and F-box and WD repeat domain containing 7 ( $F B X W 7$ ). The most common increase in the number of copy was seen in $C D X 2$. When compared to primary tumor, mutations in $K R A S$, cyclin-dependent kinase inhibitor 2A $(C D K N 2 A)$, excision repair crosscomplementing rodent repair deficiency, complementation group 2 (ERCC2) and V-Ha-Ras Harvey rat sarcoma viral oncogene homolog (HRAS) were significantly higher in BMs. All these facts demonstrate that BMs have a molecular phenotype, which is different of that of primary tumor.

Shabbir et al. investigated the frequency of HER2/neu expression in 95 cases of CRC of Pakistani patients for HER2/neu expression. Specimens obtained from almost $80 \%$ of their patients expressed HER $2 /$ neu staining but with different location in correlation with the malignancy grade of CRC. A cytoplasmic HER2/neu expression was encountered in low-grade $\mathrm{CRC}$, while membranous HER2/neu expression was identified in high grade CRC. Also, an interesting fact was reported by these authors regarding the pattern of HER2/neu staining. One-third of the mucinous-type cases showed a membranous HER2/neu expression while almost half of the nonmucinous type cases presented a cytoplasmic HER2/neu expression [33].

Wang et al. demonstrated that, in highly proliferative breast cancer subtypes, which are characterized by a poor clinical outcome, HER2/neu does not just act like a membrane tyrosine kinase inducing the activation of mitogenic signaling pathways to promote tumor growth, but also it moves to the nuclear compartment, where it functions as a transcription factor [41]. In addition, a relatively recent article published by Schillaci et al. reported that in the nucleus of breast cancer cells, ErbB-2 participates in the formation of a transcriptional complex in which it functions as a coactivator of the signal transducer and as an activator of transcription 3 (Stat3) in order to stimulate the expression of cyclin D1, i.e., a gene that induces tumoral proliferation. These authors found an important association between nuclear ErbB-2 (nuclErbB-2) and the identification of distant metastasis at the time of the diagnosis. They concluded that there could be a direct involvement of nuclErbB-2 in the progression of breast cancer [42]. In this context, it is worth to mention that the BMs from our study also showed an aberrant, strong and diffuse nuclear immunostaining for anti-HER2/neu antibody.

The prognosis of patients with BM from CRC is poor. Surgery and postoperative radiotherapy may increase survival, but the median survival time following diagnosis range between 5.3 months to 8.3 months [20]. On average, the one-year overall survival rate of these patients, regardless the treatment method, is considered to be almost 24\% [21]. To reduce morbidity and mortality through $\mathrm{BMs}$ originating in $\mathrm{CRC}$, it may be of interest to prevent the primary cancer by using antioxidants extracted from plant roots which have proven effective in digestive tract disorders [43], and if CRC is already developing it may be useful postoperative Immunoglobulin (Ig) injection of which it has been shown that could temporarily boost the patient's immunity against disease [44].

\section{a Conclusions}

BMs originating in CRC represent a rare pathology and have particular clinical and IHC aspects that could vary from one series to another series. In a few cases, BMs may be diagnosed in the absence of a known CRC diagnosis and in these situations the correct diagnosis is of interest. However, a panel of antibodies can help in establishing a correct diagnosis. Our study was among the first to analyze the HER2/neu expression pattern in $\mathrm{BMs}$ from $\mathrm{CRC}$ and we found a strong aberrant nuclear expression of this molecular marker on IHC investigation. Related to the data published so far in the literature, it is possible that HER2/neu aberrant expression in the tumoral nuclei of the BMs from our series may express the metastatic tumor cell phenotype that was previously subjected to chemo- and radiation 
therapies. As such, we suggest that HER2/neu aberrant expression in BMs originating in CRC could represent a proof for the worst prognosis of these patients.

\section{Conflict of interests}

The authors declare that they have no conflict of interests.

\section{References}

[1] Barnholtz-Sloan JS, Sloan AE, Davis FG, Vigneau FD, Lai P, Sawaya RE. Incidence proportions of brain metastases in patients diagnosed (1973 to 2001) in the Metropolitan Detroit Cancer Surveillance System. J Clin Oncol, 2004, 22(14): 2865-2872. https://doi.org/10.1200/JCO.2004.12.149 PMID: 15254054

[2] Ostrom QT, Wright $\mathrm{CH}$, Barnholtz-Sloan JS. Brain metastases: epidemiology. Handb Clin Neurol, 2018, 149:27-42. https:// doi.org/10.1016/B978-0-12-811161-1.00002-5 PMID: 29307358

[3] Gramada FM, Indrei A, lencean StM, Poeata I, Dumitrescu G Miron L. Management of unknown origin cerebral metastases. Rom Neurosurg, 2011, XVIII(1):60-67.

[4] Torre LA, Bray F, Siegel RL, Ferlay J, Lortet-Tieulent J, Jemal A. Global cancer statistics, 2012. CA Cancer J Clin, 2015, 65(2):87-108. https://doi.org/10.3322/caac.21262 PMID: 25651787

[5] Christensen TD, Spindler KL, Palshof JA, Nielsen DL. Systematic review: brain metastases from colorectal cancer - incidence and patient characteristics. BMC Cancer, 2016, 16:260. https://doi.org/10.1186/s12885-016-2290-5 PMID: 27037031 PMCID: PMC4818396

[6] Kaymak Ş, Hançerlioğulları O, İnce M, Sinan H, Demirbaş S. Precocious brain metastasis of colorectal cancer: a report of two cases. Turk J Colorectal Dis, 2017, 27(1):34-37. https:// doi.org/10.4274/tjcd.80106

[7] Mogoantă SŞ, Lungu C, Ilie C, Albu DF, Totolici B, Neamţu C, Mitrut $P$, Dogaru CA, Turculeanu A. Peritumoral inflammatory reaction in colon cancer. Histological and immunohistochemical study. Rom J Morphol Embryol, 2014, 55(4):1429-1435. PMID: 25611277

[8] Mongan JP, Fadul CE, Cole BF, Zaki BI, Suriawinata AA, Ripple GH, Tosteson TD, Pipas JM. Brain metastases from colorectal cancer: risk factors, incidence, and the possible role of chemokines. Clin Colorectal Cancer, 2009, 8(2):100 105. https://doi.org/10.3816/CCC.2009.n.016 PMID: 19739271 PMCID: PMC3909497

[9] Rahmathulla G, Toms SA, Weil RJ. The molecular biology of brain metastasis. J Oncol, 2012, 2012:723541. https://doi.org/ 10.1155/2012/723541 PMID: 22481931 PMCID: PMC3317231

[10] Kruser TJ, Chao ST, Elson P, Barnett GH, Vogelbaum MA, Angelov L, Weil RJ, Pelley R, Suh JH. Multidisciplinary management of colorectal brain metastases: a retrospective study. Cancer, 2008, 113(1):158-165. https://doi.org/10.1002/ cncr.23531 PMID: 18459179

[11] Damiens K, Ayoub JP, Lemieux B, Aubin F, Saliba W, Campeau MP, Tehfe M. Clinical features and course of brain metastases in colorectal cancer: an experience from a single institution. Curr Oncol, 2012, 19(5):254-258. https:// doi.org/10.3747/co.19.1048 PMID: 23144573 PMCID: PMC 3457876

[12] Aprile G, Zanon E, Tuniz F, laiza E, De Pauli F, Pella N Pizzolitto S, Buffoli A, Piga A, Skrap M, Fasola G. Neurosurgical management and postoperative whole-brain radiotherapy for colorectal cancer patients with symptomatic brain metastases. J Cancer Res Clin Oncol, 2009, 135(3):451-457. https://doi.org/10.1007/s00432-008-0468-1 PMID: 18779977

[13] Tapia Rico G, Price TJ, Karapetis C, Piantadosi C, Padbury R Roy A, Maddern G, Moore J, Carruthers S, Roder D, Townsend AR. Brain metastasis in advanced colorectal cancer: results from the South Australian metastatic colorectal cancer (SAmCRC) registry. Cancer Biol Med, 2017, 14(4):371-376. https://doi.org/10.20892/j.issn.2095-3941.2017.0068 PMID: 29372103 PMCID: PMC5785167

[14] Morariu SI, Duceac LD, Luca AC, Popescu F, Pavel L, Gavrilescu CM. Soil chemical pollution and aggressive pathologies. Rev Chim (Bucharest), 2018, 69(8):2278-2282. https:// doi.org/10.37358/RC.18.8.6515
[15] López-Abente G, García-Pérez J, Fernández-Navarro $P$, Boldo E, Ramis R. Colorectal cancer mortality and industrial pollution in Spain. BMC Public Health, 2012, 12:589. https:// doi.org/10.1186/1471-2458-12-589 PMID: 22852770 PMCID: PMC3490748

[16] Nozawa H, Ishihara S, Kawai K, Sasaki K, Murono K, Otani K, Nishikawa T, Tanaka T, Kiyomatsu T, Hata K, Watanabe T. Brain metastasis from colorectal cancer: predictors and treatment outcomes. Oncology, 2017, 93(5):309-314. https:// doi.org/10.1159/000478661 PMID: 28700994

[17] Alden TD, Gianino JW, Saclarides TJ. Brain metastases from colorectal cancer. Dis Colon Rectum, 1996, 39(5):541-545. https://doi.org/10.1007/BF02058708 PMID: 8620805

[18] Schouten LJ, Rutten J, Huveneers HA, Twijnstra A. Incidence of brain metastases in a cohort of patients with carcinoma of the breast, colon, kidney, and lung and melanoma. Cancer, 2002, 94(10):2698-2705. https://doi.org/10.1002/cncr.10541 PMID: 12173339

[19] Hayat MA (ed). Brain metastases from primary tumors. Vol. 1: Epidemiology, biology, and therapy. Academic Press, Elsevier, Amsterdam-Boston-Heidelberg-London-...-Tokyo, 2014, 6. https://doi.org/10.1016/C2013-0-18945-3

[20] Wroński M, Arbit E. Resection of brain metastases from colorectal carcinoma in 73 patients. Cancer, 1999, 85(8):16771685. https://doi.org/10.1002/(sici)1097-0142(19990415)85:8< 1677::aid-cncr6>3.0.co;2-c PMID: 10223560

[21] Silva IL, Iskandarani M, Hotouras A, Murphy J, Bhan C, Adada B, Wexner SD. A systematic review to assess the management of patients with cerebral metastases secondary to colorectal cancer. Tech Coloproctol, 2017, 21(11):847-852. https://doi.org/10.1007/s10151-017-1707-8 PMID: 29124419

[22] Tevlin R, Larkin JO, Hyland JM, O'Connell PR, Winter DC. Brain metastasis from colorectal carcinoma: a single cancer centre experience. Ir J Med Sci, 2015, 184(3):673-675. https:// doi.org/10.1007/s11845-015-1272-y PMID: 25802245

[23] Sun Z, Sun Y, Tan L, He J, Li X, She C, Li W. [Clinical features and prognostic factors of brain metastasis from colorectal cancer]. Zhonghua Zhong Liu Za Zhi, 2016, 38(1): 63-68. https://doi.org/10.3760/cma.j.issn.0253-3766.2016.01. 012 PMID: 26796809

[24] Mege D, Ouaissi M, Fuks D, Metellus P, Peltier J, Dufour H, Regimbeau JM, Dahan L, Sielezneff I, Sastre B. Patients with brain metastases from colorectal cancer are not condemned. Anticancer Res, 2013, 33(12):5645-5648. PMID: 24324111

[25] Taraşi I, Dumitrescu GF, Indrei A, Plămădeală P, Trifan A, Stanciu C. Screening for colorectal cancer with fecal occult blood testing and colonoscopy: correlation of clinical data, site, size and disease's stage. J Surg (Jurnalul de Chirurgie), 2009, 5(2):153-164.

[26] Mogoantă SŞ, Vasile I, Totolici B, Neamţu C, Streba L, Busuioc CJ, Mateescu GO. Colorectal cancer - clinical and morphological aspects. Rom J Morphol Embryol, 2014, 55(1): 103-110. PMID: 24715173

[27] Wang J, Li S, Liu Y, Zhang C, Li H, Lai B. Metastatic patterns and survival outcomes in patients with stage IV colon cancer: a population-based analysis. Cancer Med, 2020, 9(1):361373. https://doi.org/10.1002/cam4.2673 PMID: 31693304 PMCID: PMC6943094

[28] Botiralieva G, Navruzov S, Nishanov D. 204P: Clinical value of CDX2 in the differential diagnosis of pulmonary adenocarcinoma from metastatic colorectal carcinoma. Abstracts ELCC 2016. J Thoracic Oncol, 2016, 11(4 Suppl):S145. https://doi.org/10.1016/S1556-0864(16)30312-4

[29] Werling RW, Yaziji H, Bacchi CE, Gown AM. CDX2, a highly sensitive and specific marker of adenocarcinomas of intestinal origin: an immunohistochemical survey of 476 primary and metastatic carcinomas. Am J Surg Pathol, 2003, 27(3):303310. https://doi.org/10.1097/00000478-200303000-00003 PMID: 12604886

[30] Pekmezci M, Perry A. Neuropathology of brain metastases. Surg Neurol Int, 2013, 4(Suppl 4):S245-S255. https://doi.org/ 10.4103/2152-7806.111302 PMID: 23717796 PMCID: PMC 3656562

[31] Bae JM, Lee TH, Cho NY, Kim TY, Kang GH. Loss of CDX2 expression is associated with poor prognosis in colorectal cancer patients. World J Gastroenterol, 2015, 21(5):14571467. https://doi.org/10.3748/wjg.v21.i5.1457 PMID: 25663765 PMCID: PMC4316088 
[32] Shigematsu Y, Inamura K, Yamamoto N, Mise Y, Saiura A, Ishikawa $Y$, Takahashi $S$, Kanda $H$. Impact of CDX2 expression status on the survival of patients after curative resection for colorectal cancer liver metastasis. BMC Cancer, 2018, 18(1):980. https://doi.org/10.1186/s12885-018-4902-8 PMID: 30326864 PMCID: PMC6192098

[33] Shabbir A, Mirza T, Khalid AB, Qureshi MA, Asim SA Frequency of Her2/neu expression in colorectal adenocarcinoma: a study from developing South Asian Country. BMC, 2016, 16(1):855. https://doi.org/10.1186/s12885-0162912-y PMID: 27821098 PMCID: PMC5100101

[34] Schuell B, Gruenberger T, Scheithauer W, Zielinski Ch, Wrba F HER 2/neu protein expression in colorectal cancer. BMC Cancer, 2006, 6:123. https://doi.org/10.1186/1471-2407-6123 PMID: 16681853 PMCID: PMC1475876

[35] Sayadnejad N, Firouzjahi A, Shafaee S, Golshahi H, Sokouti Z, Gholinia H, Ranaee M. Immunohistochemical study of HER2/neu expression in colorectal cancer and its relation to other clinicopathological criteria and prognostic factors. Int $\mathrm{J}$ Cancer Manag, 2017, 10(5):e5700. https://doi.org/10.5812/ijcm.5700

[36] Ingold Heppner B, Behrens HM, Balschun K, Haag J, Krüger S, Becker T, Röcken C. HER2/neu testing in primary colorectal carcinoma. Br J Cancer, 2014, 111(10):1977-1984. https:// doi.org/10.1038/bjc.2014.483 PMID: 25211663 PMCID: PMC 4229629

[37] Park DI, Kang MS, Oh SJ, Kim HJ, Cho YK, Sohn Cl, Jeon WK, Kim BI, Han WK, Kim H, Ryu SH, Sepulveda AR. HER-2/ neu overexpression is an independent prognostic factor in colorectal cancer. Int J Colorectal Dis, 2007, 22(5):491-497. https://doi.org/10.1007/s00384-006-0192-8 PMID: 16947041

[38] Aprile G, De Maglio G, Menis J, Casagrande M, Tuniz F, Pisa EF, Fontanella C, Skrap M, Beltrami AC, Fasola G, Pizzolitto S. HER-2 expression in brain metastases from colorectal cancer and corresponding primary tumors: a case cohort series. Int J Mol Sci, 2013, 14(2):2370-2387. https:// doi.org/10.3390/ijms14022370 PMID: 23348930 PMCID: PMC 3587992
[39] Sun J, Wang C, Zhang Y, Xu L, Fang W, Zhu Y, Zheng Y, Chen X, Xie X, Hu X, Hu W, Zheng J, Li P, Yu J, Mei Z, Cai X, Wang B, Hu Z, Shu Y, Shen H, Gu Y. Genomic signatures reveal DNA damage response deficiency in colorectal cancer brain metastases. Nat Commun, 2019, 10(1):3190. https:// doi.org/10.1038/s41467-019-10987-3 PMID: 31320627 PMCID: PMC6639368

[40] Battaglin F, Xiu J, Baca Y, Goldberg RM, Grothey A, Shields AF, Seeber A, Salem ME, Puccini A, Tokunaga R, Naseem M, Arai H, Wang J, Berger MD, Zhang W, Philip PA, Marshall JL, Korn WM, Lenz HJ. Comprehensive molecular characterization of brain metastases (BM) from colorectal cancer (CRC). Ann Oncol, 2019, 30(Suppl 5):v760-v796. https://doi.org/10.1093/ annonc/mdz268.009

[41] Wang SC, Lien HC, Xia W, Chen IF, Lo HW, Wang Z, AliSeyed M, Lee DF, Bartholomeusz G, Ou-Yang F, Giri DK, Hung MC. Binding at and transactivation of the COX-2 promoter by nuclear tyrosine kinase receptor ErbB-2. Cancer Cell, 2004, 6(3):251-261. https://doi.org/10.1016/j.ccr.2004.07.012 PMID: 15380516

[42] Schillaci R, Guzmán P, Cayrol F, Beguelin W, Díaz Flaqué MC, Proietti CJ, Pineda V, Palazzi J, Frahm I, Charreau EH, Maronna E, Roa JC, Elizalde PV. Clinical relevance of ErbB-2/ HER2 nuclear expression in breast cancer. BMC Cancer, 2012, 12:74. https://doi.org/10.1186/1471-2407-12-74 PMID: 22356700 PMCID: PMC3342900

[43] Vasincu A, Paulsen BS, Diallo D, Vasincu I, Aprotosoaie AC Bild V, Charalambous C, Constantinou AI, Miron A, Gavrilescu CM. Vernonia kotschyana roots: therapeutic potential via antioxidant activity. Molecules, 2014, 19(11):19114-19136. https://doi.org/10.3390/molecules191119114 PMID: 25415475 PMCID: PMC6271907

[44] Sava A, Ciobanu Apostol DG, Şapte E, lonescu L, Costea CF Ciocoiu M, Dumitrescu GF, Stan Cl, Slănină AM, Cobzaru RG, Costache II. Long-term survival in a patient with advanced gastric cancer and metachronous right-sided colon cancer. Rom J Morphol Embryol, 2017, 58(4):1569-1577. PMID: 29556659

\section{Corresponding authors}

Delia Gabriela Ciobanu Apostol, Assistant Professor, MD, PhD, Department of Morpho-Functional Sciences I, Grigore T. Popa University of Medicine and Pharmacy, 16 University Street, 700115 laşi, Romania; Phone +40722870 141, e-mail: delia.ciobanu@umfiasi.ro

Dana Mihaela Turliuc, Associate Professor, MD, PhD, Department of Surgery II, Grigore T. Popa University of Medicine and Pharmacy, 16 University Street, 700115 laşi, Romania; Phone +40744-762 927, e-mail: turliuc_dana@yahoo.com 